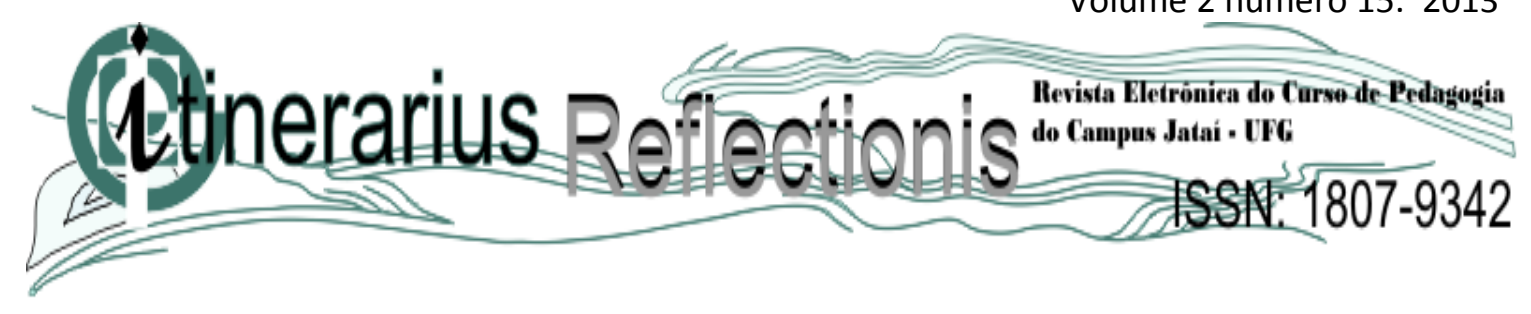

\title{
APRENDIZAGEM SIGNIFICATIVA: REVISÃO TEÓRICA E APRESENTAÇÃO DE UM INSTRUMENTO PARA APLICAÇÃO EM SALA DE AULA
}

Ms. Wanderley Pivatto

Universidade Federal de Santa Catarina, UFSC,SC.

Resumo: Muitos são os instrumentos existentes para contribuir junto ao professor no processo de ensino. A construção de mapas conceituais se constitui como um deles, cuja finalidade é auxiliar no desenvolvimento cognitivo dos estudantes que, no contexto deste artigo, engloba a aquisição de conhecimento e evolução conceitual, visando facilitar o planejamento do processo de ensino e aprendizagem. Embora este instrumento seja considerado adequado para utilização em sala de aula, poucos professores fazem uso dele por não conhecerem uma maneira adequada de utilizá-lo. Este artigo tem como objetivo apresentar uma revisão sobre a Teoria da Aprendizagem Significativa, assim como esclarecer a forma como ela pode ser utilizada dentro do contexto de ensino.

Palavras-chave: Aprendizagem Significativa. Instrumento. Desenvolvimento cognitivo. Processo cognitivo.

Abstract: There are many tools available to help with the teacher in the teaching process. The construction of concept maps constitute themselves a instrument, whose purpose is to assist in the cognitive development of students, in the context of this article, includes knowledge acquisition and conceptual evolution in order to facilitate the planning of teaching and learning. Although this instrument is considered suitable for use in the classroom, many teachers make use of it by not knowing an appropriate way to use them. This article aims to present a review on the Theory of Meaningful Learning, as well as guidance on how it can be used within the context of teaching.

Keywords: Meaningful learning. Instrument. Cognitive development. Cognitive proc 


\section{(1titinerarius Relilectionis}

\section{Introdução}

Atualmente, muitas escolas continuam dominadas por uma concepção pedagógica tradicional, na qual se ensina uma grande quantidade de informação, geralmente tendo como base o programa do próprio livro didático, pois revela Behrens (2013), este não forma proposições significativas para os estudantes, o que impede uma compreensão das frases ou sentenças através de seus processos cognitivos habituais. Por consequência, as crianças apresentam muita dificuldade para aprender a ler e calcular, pois parte do material utilizado não lhe é significativo. Para Fernandes (2001) e Dryden (1996), ao tentar preparar materiais de leitura considerados fáceis para o estudante, os professores produzem materiais essencialmente sem sentido que anulam o poder da aprendizagem significativa e da percepção.

Diante deste contexto, Freire (1997) cita que o ato educacional impõe mais do que nunca uma atitude intencional daquele que educa. É necessária uma vontade explícita de intervir no processo de aprendizagem do estudante, que se traduz numa série de decisões de ordem pedagógica, que envolve todo processo educativo desde a elaboração do currículo até as práticas escolares da sala de aula.

Behrens (2013) e Fergunson (1992) relembram que os currículos escolares devam ser organizados em torno de um conjunto de disciplinas nitidamente diferenciadas, dominados pela ritualização dos procedimentos escolares, algumas vezes já obsoletos, cujos conteúdos se apoiam em uma organização rigidamente estabelecida, desconectada das experiências dos próprios estudantes. Mesmo com todo avanço das pesquisas em educação, de ciência e tecnologia, as aulas assemelham-se mais a modelos do início do século, tendo como perspectiva a metodologia dominante, a exposição, a exercitação e a comprovação da aprendizagem por meio de atividades repetitivas, enfatizando mais a memória do que a própria compreensão.

A escola organizada sob tal enfoque, cita Libâneo (1998) carece de significado para os estudantes, pois corre-se o risco do abandono, da desmotivação e até mesmo o da rebeldia, que entre outras formas se manifesta por meio de atitudes de agressividade 


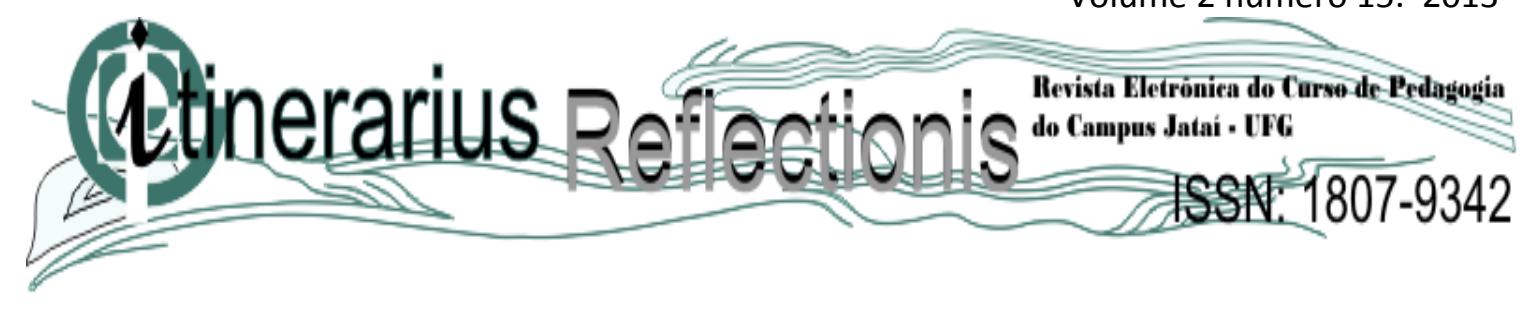

e indisciplina. A resposta que a escola apresenta a esta situação, muitas vezes, é acentuar procedimentos repressivos, impor recursos disciplinares ou atribuir esses problemas a fatores externos, tais como o desequilíbrio familiar, a imaturidade do estudante ou os incontestáveis problemas de aprendizagem.

Aprender deve ser entendido como compreensão de significados relacionados às experiências anteriores e às vivencias pessoais dos estudantes incentivando maior aprendizagem, desencadeando modificações de comportamento e contribuindo para a utilização do que é aprendido em diferentes situações. O discurso de Pimentel (1993) sobre a concretização da aprendizagem significativa deve ocorrer por meio da interação entre o processo de ensino e o de aprendizagem, no entanto, é preciso mais do que novas metodologias, recursos didáticos ou até mesmo de um aparato tecnológico, como afirma Veiga (1996, p. 36):

É preciso edita-se que o professor deva ser um comunicador que desperte o interesse do aluno e considere os aspectos psicológicos envolvidos no processo de aprendizagem. O educador não deve deter-se apenas em codificar sua mensagem, mas torná-las decodificáveis para o aluno.

Para tratar destas questões aqui expostas, este artigo encontra-se dividido em três partes. A primeira, apresenta uma revisão teórica da Teoria da Aprendizagem Significativa. A segunda, apresentaremos dois instrumentos didáticos para promover a aprendizagem significativa, a construção de mapas conceituais e atividades sequenciadas. Na terceira, é exposto considerações de ordem geral sobre ensino e aprendizagem.

\section{Revisão teórica da Aprendizagem Significativa}

A teoria da aprendizagem significativa foi formulada inicialmente pelo psicólogo norte americano David Paul Ausubel. As ideias de Ausubel, cujas formulações iniciais são dos anos 60, se encontram entre as primeiras propostas psicoeducativas em sua obra "Psicologia Educacional", recebendo colaborações em 1980 de Joseph Donald Novak e Helen Hanesian, acerca de fatores sociais, cognitivos e afetivos na aprendizagem. 


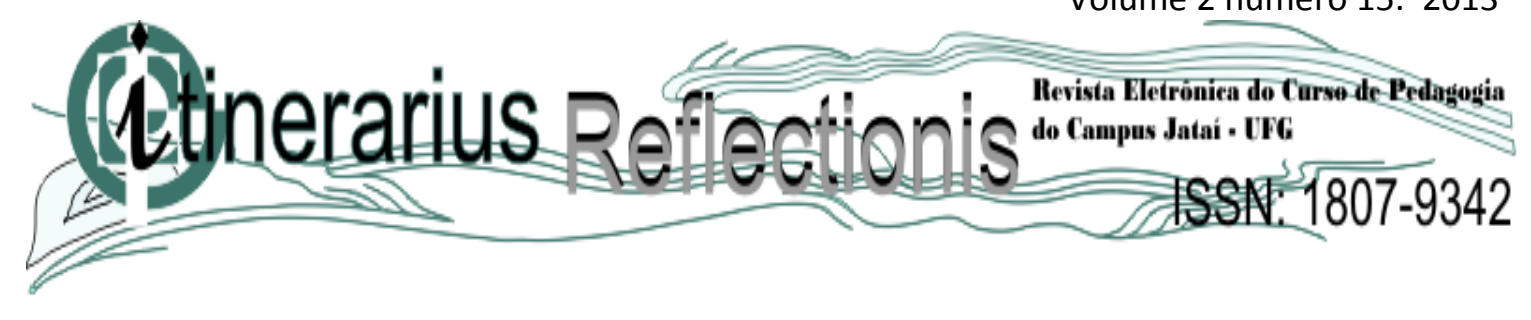

[...] é essencial levar - se em consideração as complexidades provenientes da situação de classe de aula, estes por sua vez, incluem a presença de muitos alunos de motivação, prontidão e aptidões desiguais; as dificuldades de comunicação entre professor e aluno; as características particulares de cada disciplina que esta sendo ensinada; e as características das idades dos alunos (AUSUBEL; NOVAK; HANESIAN, 1980, p. 5).

Para os autores, basicamente, a ideia central de aprendizagem significativa é uma reorganização clara da estrutura cognitiva, isto é, um processo pelo qual uma nova informação se relaciona com um aspecto relevante na estrutura do conhecimento do estudante. A aprendizagem significativa é uma tentativa de fornecer sentido ou estabelecer relações de modo não arbitrário e substancial (não ao pé da letra) entre os novos conhecimentos e os conceitos que existem no estudante. Em contraponto à aprendizagem significativa, surge a aprendizagem mecânica que para Ausubel, Novak e Hanesian (1980) é o tipo de aprendizagem, diferentemente do processo significativo, ocorrendo quando o estudante é apresentado a um novo conhecimento, e este, por motivos variados, não o relaciona com algum conceito que já exista em sua mente, simplesmente, incorpora - se na sua estrutura cognitiva de maneira arbitrária e não substantiva.

A aprendizagem (significativa ou mecânica) ocorre por meio de recepção, enfatizado por Moreira (2010) como aquela em que todo o conteúdo vai ser aprendido é apresentada ao estudante na forma final ou por descoberta onde os conceitos não são fornecidos, mas deve ser "descoberto" pelo estudante antes que possa ser incorporado significativamente na sua estrutura cognitiva. No entanto, a aprendizagem por descoberta, não é necessariamente significativa, nem aprendizagem por recepção é obrigatoriamente mecânica, mas se apresentam como um continuum. Para o autor, uma posição mais defensável é de que tanto a aprendizagem receptiva ou por descoberta podem ser mecânicas ou significativas dependendo das condições que ocorre a aprendizagem.

Em ambos os casos (recepção ou descoberta) a aprendizagem significativa ocorre quando há um processo de interação no qual os conceitos mais relevantes e inclusivos (subsunçores) integram com o novo material a ser aprendido. A 


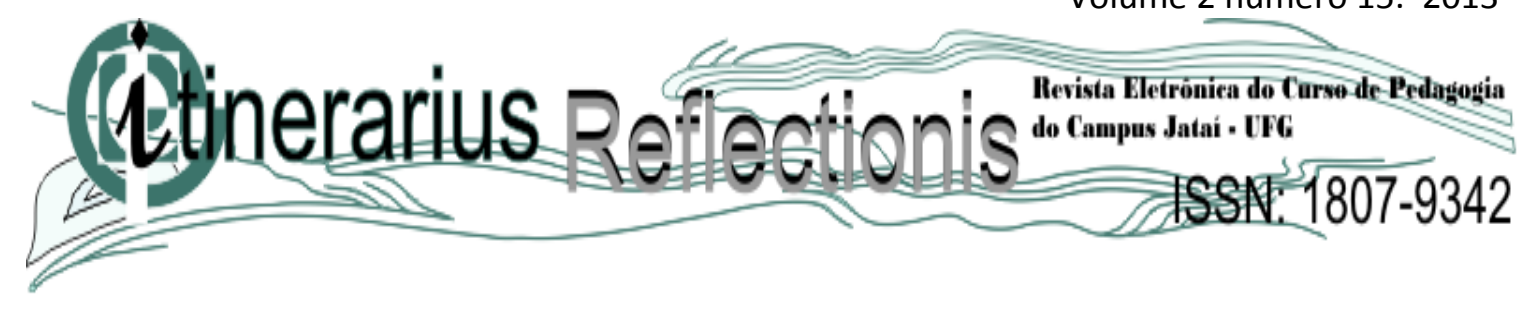

aprendizagem significativa é caracterizada por uma interação entre os aspectos específicos e relevantes da estrutura cognitiva e as novas informações, por meio das quais essas adquirem significado e são integradas a uma estrutura hierárquica altamente organizada de subsunçores de maneira não arbitrária e não literal.

A aprendizagem significativa deve preponderar em relação a aprendizagem de associações arbitrárias, organizacionalmente isoladas, mecânica. Para isso, algumas condições são apontadas por Ausubel, Novak e Hanesian (1980):

- A existência prévia de conceitos subsunçores, compreendido pelos autores como um conceito já existente na estrutura cognitiva, capaz de servir de ancoradouro a uma nova informação, de modo que esta adquira significado para o estudante;

- O estudante precisa ter uma disposição para aprender: se o indivíduo quiser memorizar o conteúdo arbitrária e literalmente, então a aprendizagem será mecânica. A aprendizagem significativa pressupõe que o estudante manifeste uma disposição para a aprendizagem, ou seja, disposição para se relacionar de forma não arbitrária e substantiva ao novo conhecimento;

- O conteúdo escolar a ser aprendido tem que ser potencialmente significativo, ou seja, deve estar relacionado à estrutura cognitiva do estudante, portanto, devem estar disponíveis em sua estrutura cognitiva subsunçores adequados.

A partir destas condições, Pozo (1998) cita que é preciso entender que existe uma modificação no conhecimento, balizado pela manifestação de interesse em aprender por parte do estudante e o material deverá ser potencialmente significativo. A percepção de uma aprendizagem significativa se consolida por meio de um processo que é considerado dinâmico e não unilateral, no qual os estudantes carregados de interconexões mentais e saberes se tornam peça fundamental nesse movimento de construção do conhecimento, contudo, se o estudante deseja simplesmente memorizar, o processo de aprendizagem será mecânico e sem significado.

No curso da aprendizagem significativa, Moreira (2010) enfatiza que os conceitos interagem com os novos conteúdos, servindo de base para a atribuição de novos significados que também se modificam. Essa mudança progressiva vai tornando 


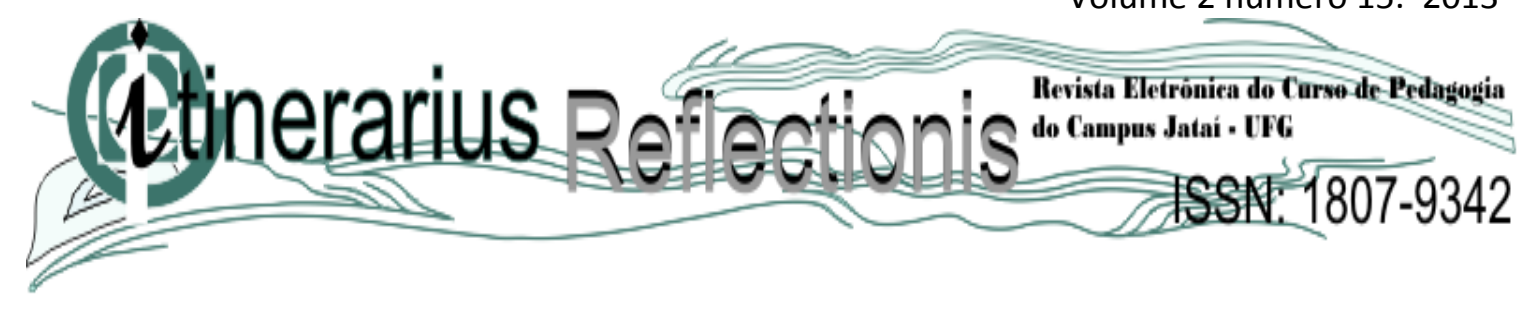

um subsunçor mais elaborado, mais diferenciado, capaz de servir de âncora para a aquisição de novos conhecimentos, processo este que Ausubel chama de diferenciação progressiva.

Outro processo que ocorre no encadeamento da aprendizagem significativa é o que Moreira (2010) denomina de estabelecimento de relações entre ideias, que podem ser conceitos, proposições que já se encontram na estrutura cognitiva. A existência de conceitos estáveis e com certo grau de diferenciação são relacionados com outros conceitos, passando a adquirir novos significados levando a uma reorganização da estrutura cognitiva. Essa reorganização de conceitos é conhecida por reconciliação integrativa.

A busca de indícios para a ocorrência de uma aprendizagem significativa não é uma tarefa simples. Verificar se uma aprendizagem ocorreu, segundo Ausubel, Novak e Hanesian (1980), simplesmente perguntando ao estudante os atributos de um conceito ou proposição é arriscado, haja vista a possibilidade da utilização de respostas mecanicamente memorizadas. Os autores entendem que é necessária uma compreensão no domínio dos significados que se apresentam de forma clara, precisa, diferenciados e transferíveis.

Uma sugestão apresentada por Ausubel e defendida por Moreira e Masini (2001), com objetivo de evitar uma simulação da aprendizagem significativa, é utilizar situações que sejam novas e não familiares, exigindo máxima transformação do conhecimento existente. Há diversas alternativas para verificação da ocorrência da aprendizagem significativa, como tarefas de aprendizagem sequencialmente vinculadas, servindo de apoio a etapas posteriores da atividade, a resolução de problemas bem como a utilização de mapas conceituais.

$\mathrm{Na}$ busca de indícios de uma possível aprendizagem significativa, um importante aspecto é partir dos conhecimentos que os estudantes trazem para dentro da sala de aula. "Se tivéssemos que reduzir toda a psicologia educacional a um único princípio diríamos que o fator singular mais importante que influencia a aprendizagem é aquilo que o aprendiz já sabe, descubra isso e baseie - se nisso seus ensinamentos" 


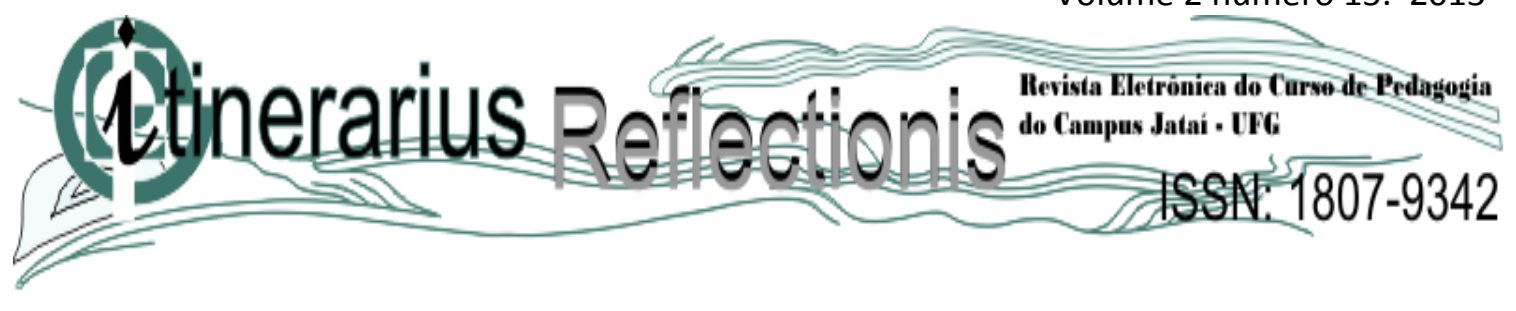

(AUSUBEL; NOVAK; HANESIAN, 1980, p. 137). Nesta vertente, o projeto educativo do professor deve está direcionado para o desenvolvimento cognitivo dos estudantes, priorizando os conhecimentos prévios, reconhecido que raramente vem marcado por estudos avançados, servindo assim de ancoragem para as novas ideias e conceitos, constituindo a base fundamental para do processo de aprendizagem.

\subsection{Formas de aprendizagem significativa}

Durante o processo da aprendizagem significativa, a nova informação não estabelece uma espécie de elo com os elementos preexistentes da estrutura cognitiva, ao contrário, esses elos só ocorrem na aprendizagem automática. $\mathrm{Na}$ aprendizagem significativa, há uma mudança tanto na nova informação como no subsunçores com a qual o novo conhecimento estabelece relação, sendo que o resultado dessa interação é a assimilação de significados.

Segundo Moreira e Masini (2001) a assimilação é um processo que ocorre quando um conceito ou proposição potencialmente significativa é assimilado sob um ideia ou conceito mais inclusivo, já existente na estrutura cognitiva. A assimilação é compreendida como um relacionamento entre os aspectos relevantes, preexistentes da estrutura cognitiva, e tanto a nova informação como a preexistente são modificadas no processo. A teoria ausubeliana apresenta três formas de aprendizagem significativa, segundo a teoria da assimilação: a subordinada, superordenada e a combinatória.

\section{Aprendizagem subordinada}

Segundo Ausubel, a maior incidência de aprendizagem significativa é do tipo subordinada, ou seja, a nova ideia aprendida se encontra hierarquicamente subordinada a ideia preexistente. Coll, Marchesi e Palácios (2007) comentam que a estrutura cognitiva do sujeito responde a uma organização hierárquica na qual os conceitos se conectam entre si mediante relações de subordinação, dos mais gerais aos mais específicos.

\section{Aprendizagem superordenada}




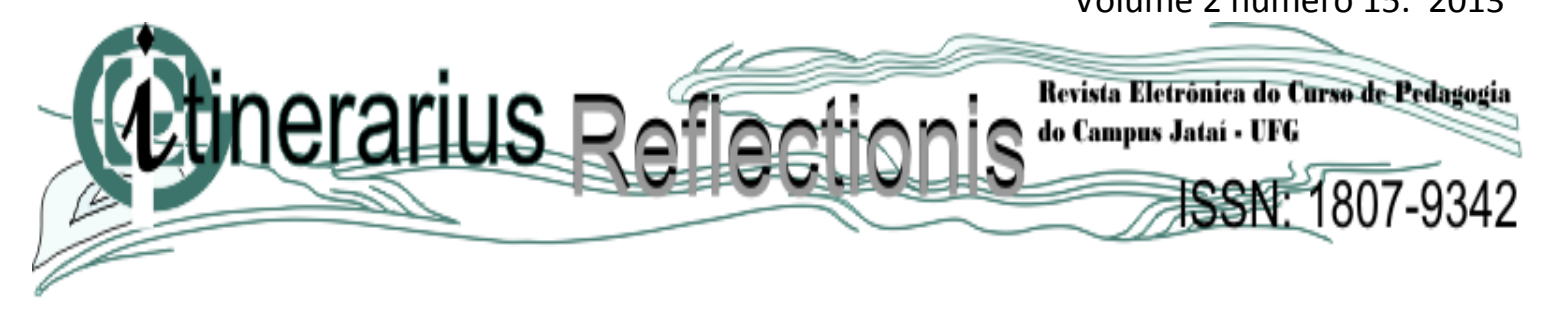

Nesta forma de aprendizagem significativa o novo conceito é mais geral e inclusivo que os conceitos subsunçores. Ocorre quando um conceito ou proposição mais geral do que algumas ideias já estabelecidas na estrutura cognitiva do estudante, é adquirido e passa a ser assimilado. Para Ausubel, Novak e Hanesian (1980) a nova aprendizagem será superordenada quando se aprende uma nova proposição inclusiva que condicionará o surgimento de várias ideias, ocorrendo no curso do raciocínio ou quando o material apresentando é organizado indutivamente ou envolve a síntese de ideias compostas.

\section{Aprendizagem combinatória}

A aprendizagem de novas proposições que não apresentam relação subordinada nem superordenada com ideias relevantes já adquiridas anteriormente na estrutura cognitiva do estudante é denominada aprendizagem combinatória. Conforme Pozo (1998) na aprendizagem significativa combinatória, a ideia nova e as ideias já estabelecidas não estão relacionadas hierarquicamente, porém se encontram no mesmo nível, não sendo nem mais específica nem mais inclusiva do que outras ideias. Ao contrário das proposições subordinadas e superordenadas, a combinatória não é relacionável a nenhuma ideia particular da estrutura cognitiva. A figura 1 apresenta um mapa conceitual sobre alguns conceitos básicos da teoria ausubeliana. 

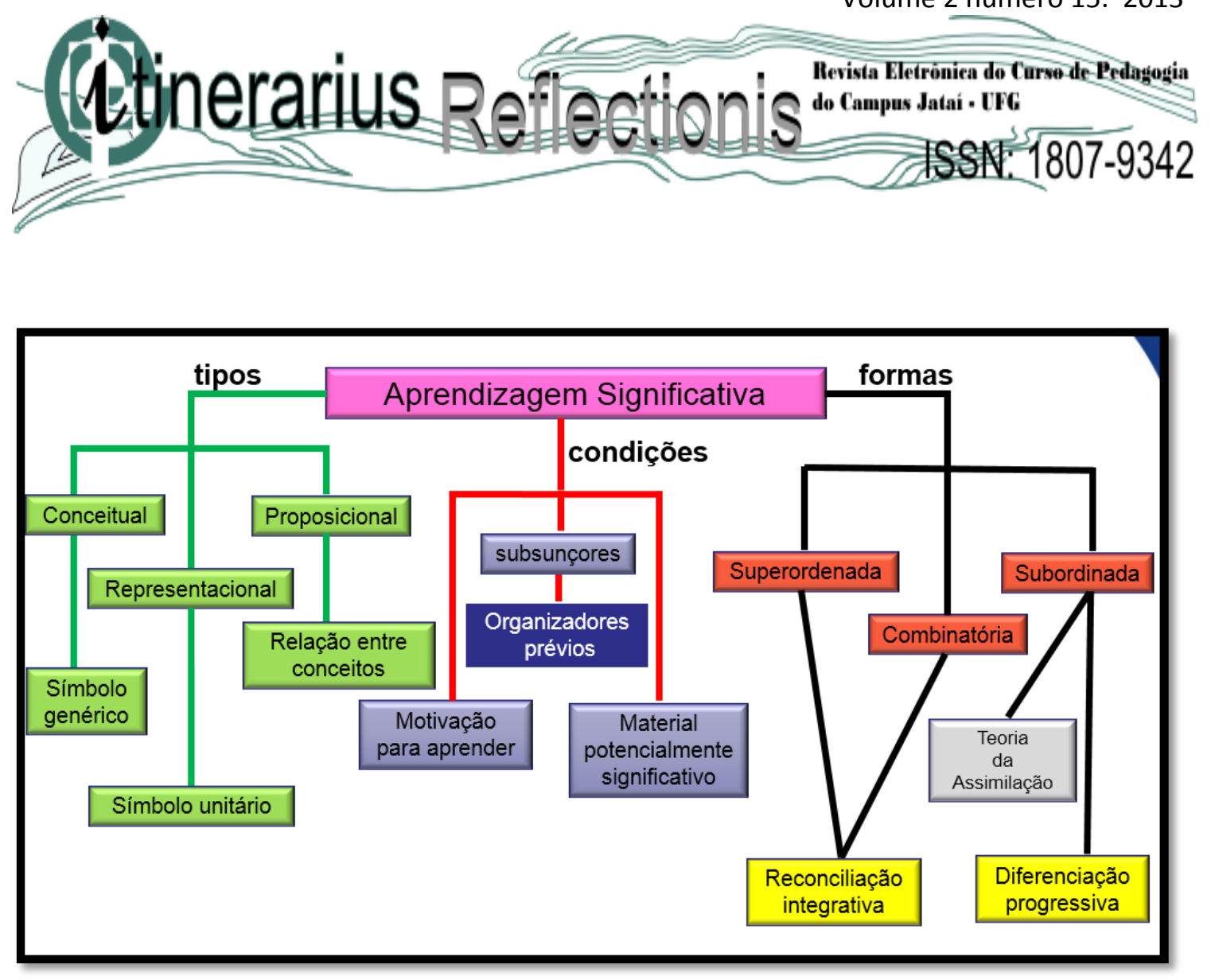

Figura 1: Conceitos pertencentes a teoria ausubeliana Fonte: Elaborado pelo autor

\section{O instrumento didático: mapa conceitual}

Uma maneira de identificar indícios de aprendizagem significativa é o uso de mapas conceituais, entendido por Moreira e Buchweitz (1993) como um instrumento didático para mostrar as relações entre os conceitos que são ensinados em uma aula, em uma unidade de estudo ou em um curso inteiro. Esse instrumento foi desenvolvido no início da década de 1970 por Joseph Novak e seus colaboradores na Universidade de Cornell, nos Estados Unidos, decorrente da teoria cognitivista de David Paul Ausubel, criada em 1963, em New York.

Para Novak e Gowin (1996), o mapa conceitual é um recurso para representar o conjunto de significados conceituais incluídos numa estrutura de proposições. Para os autores, uma proposição consiste em dois ou mais termos conceituais ligados por palavras de modo a formar uma unidade semântica. Por exemplo, "o céu é azul" representa um mapa conceitual simples, formado por uma proposição válida referente aos conceitos "céu" e "azul". Os mapas conceituais representam uma estrutura que vai 


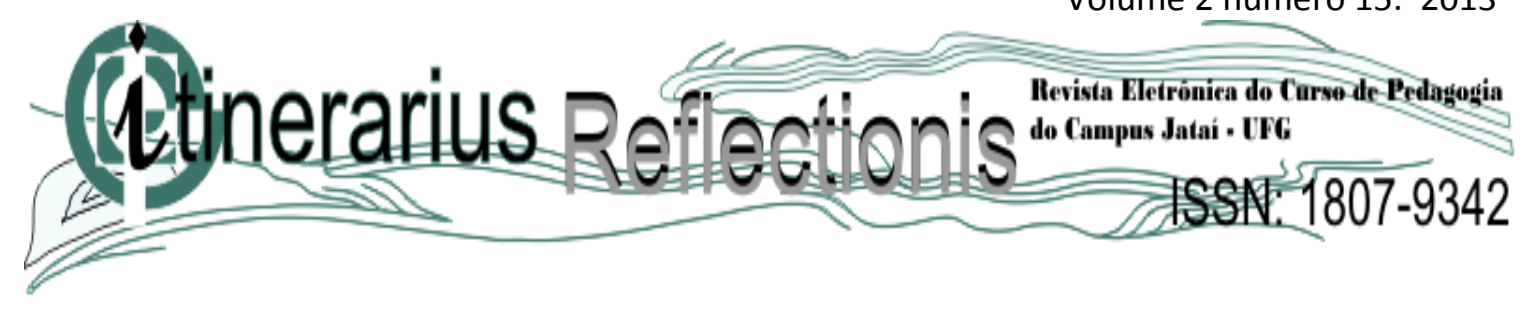

desde os conceitos mais abrangentes até os menos inclusivos. São utilizados para auxiliar a ordenação e a sequência hierarquizada dos conteúdos de forma a oferecer estímulos adequados ao estudante (NOVAK; CAÑAS, 2012).

Lima (2004) define mapa conceitual como uma técnica de organização do conhecimento ou a representação gráfica de uma estrutura de conhecimento demonstrada hierarquicamente, apresentado por formas e representações condizentes com a maneira como os conceitos são relacionados, diferenciados e organizados. Embora tenham uma organização hierárquica e muitas vezes incluam setas, tais diagramas não devem ser confundidos com organogramas.

\begin{abstract}
Os mapas conceituais podem ser usados para mostrar relações significativas entre conceitos ensinados em uma única aula, em uma unidade de estudo ou em um curso inteiro. São representações concisas das estruturas conceituais que estão sendo ensinadas e, como tal, provavelmente facilitam a aprendizagem dessas estruturas. Entretanto, diferentemente de outros materiais didáticos, mapas conceituais não são autoinstrutivos: devem ser explicados pelo professor. Além disso, embora possam ser usados para dar uma visão geral do tema em estudo, é preferível usá-los quando os alunos já têm certa familiaridade com o assunto, de modo que sejam potencialmente significativos e permitam a integração, reconciliação e diferenciação de significados de conceitos (MOREIRA, 2010, p. 17).
\end{abstract}

A construção de mapas conceituais possibilita uma estruturação hierárquica dos conceitos, tanto por diferenciação progressiva como por reconciliação integrativa. $\mathrm{O}$ princípio da diferenciação progressiva procede de maneira hierárquica, indo das ideias mais gerais para as mais específicas, enquanto no princípio da reconciliação integrativa, consiste basicamente no delineamento explícito das relações entre ideias.

O princípio de Ausubel da diferenciação progressiva estabelece que a aprendizagem significativa é um processo contínuo, no qual novos conceitos adquirem maior significado à medida que são alcançadas novas relações (ligações preposicionais). Assim, os conceitos nunca são "finalmente aprendidos", mas sim permanentemente enriquecidos, modificados e tornados mais explícitos e inclusivos à medida que se forem progressivamente diferenciando. A aprendizagem é o resultado de uma mudança do significado da experiência, e os mapas conceituais são um método de mostrar, tanto ao aluno como ao professor, que ocorreu realmente uma reorganização cognitiva (NOVAK; GOWIN, 1996, p. 114).

$\mathrm{Na}$ medida em que os estudantes interagem com mapas conceituais para realizar ligações cruzadas, reconciliar e diferenciar conceitos, eles estarão usando o mapeamento 


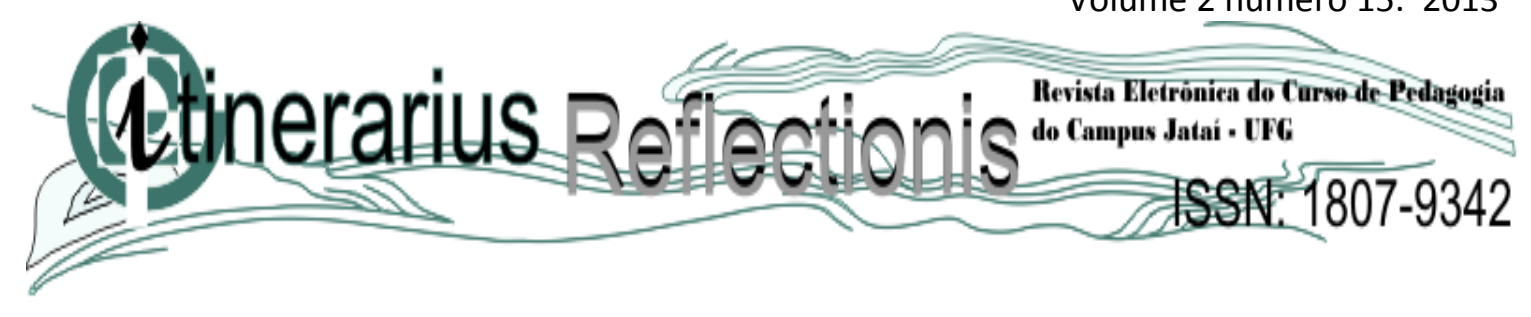

conceitual como um recurso de aprendizagem. Enquanto instrumento de avaliação, podem ser usados para obter uma visualização da organização conceitual que é atribuído ao conhecimento. Moreira (2010) relembra que um professor nunca deve apresentar aos estudantes o mapa conceitual de certo conteúdo, e sim, um mapa para esse conteúdo, segundo os significados que ele atribui aos conceitos e às relações significativas entre eles. O professor não deve esperar que o estudante apresente em uma avaliação um mapa conceitual "perfeito" diante de certo conteúdo. O que o estudante evidencia é o seu mapa e o importante não é se está correto ou errado, mas sim se existe nele indícios de que ocorreu uma aprendizagem significativa. No momento em que o professor apresentar para o estudante um mapa conceitual como sendo o ideal ou no momento em que é exigido um mapa correto estará promovendo à aprendizagem mecânica em detrimento a significativa (MOREIRA, 2010). Para o autor, o professor ao ensinar certo conteúdo tem a intenção de fazer com que o estudante adquira determinados significados de conceitos que são aceitos no contexto da matéria de ensino, no entanto, relembra que não há necessidade de atribuir pontos a construção do mapa conceitual, mas, é importante procurar explicações orais ou escritas que evidenciam a aprendizagem significativa.

\subsection{Indícios de aprendizagem significativa por meio de mapas conceituais}

Em um ambiente escolar, a aprendizagem significativa embora favorecida por relações interpessoais implica em um processo de construção de significado, portanto, é algo pessoal. Para Zabala (2007), mesmo que a aprendizagem esteja apoiada por processos compartilhados deve ser considerado pessoal. Ao considerar este fato, os mapas conceituais permitem uma avaliação individual cujo objetivo é explicitar como os estudantes compreendem determinados conteúdos. Os mapas conceituais permitem ao professor realizar observações acerca da estrutura proposicional, bem como, viabilizar a análise de ligações cruzadas ou concepções alternativas, indicativos de diferenciação dos conceitos na estrutura cognitiva do estudante referentes a uma determinada área de conhecimento (NOVAK; GOWIN, 1996). 


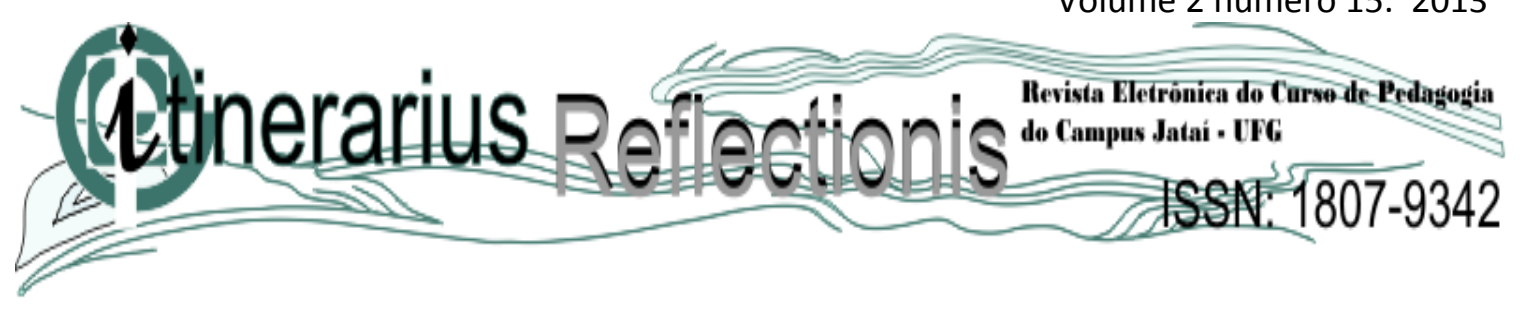

$\mathrm{Na}$ utilização de mapas conceituais, o objetivo é buscar indícios de aprendizagem significativa, porém, é preciso lembrar que a aprendizagem mecânica ou memorística e aprendizagem significativa são dois extremos de um "continuum", e que, portanto, os estudantes podem construir mapas conceituais desconsiderando conceitos relevantes à sua aprendizagem. De acordo com Ausubel, Novak e Hanesian (1980) é possível caminhar em direção à aprendizagem significativa e isto depende dos fatores contextuais e da intenção do estudante com o material de ensino. Um posicionamento extremo não é adequado quando se considera a avaliação e aprendizagem significativa. A análise acerca dos mapas, conforme Moreira (2010), deve buscar componentes sinalizadores de diferenciação progressiva, reconciliação integrativa e ligações cruzadas. Na figura 2 é apresentado um mapa conceitual ilustrando a diferenciação progressiva, a reconciliação integrativa e ligação cruzada.

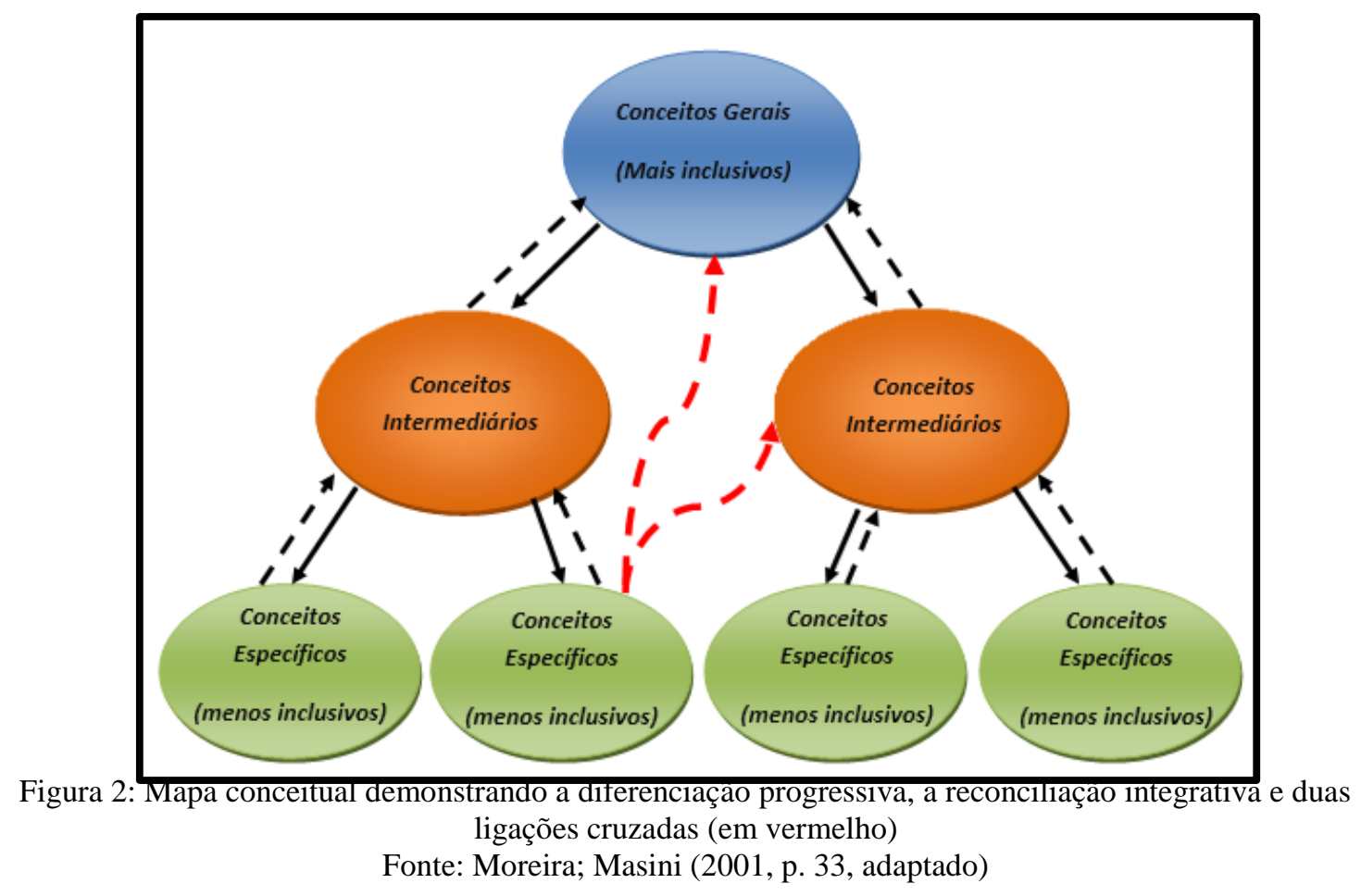

Moreira e Mazini (2001) relembram que a criatividade é muitas vezes difícil de ser reconhecida e ainda mais difícil de ser apresentada aos outros estudantes. A realização de reconciliações integrativas em um mapa conceitual pode revelar novas 


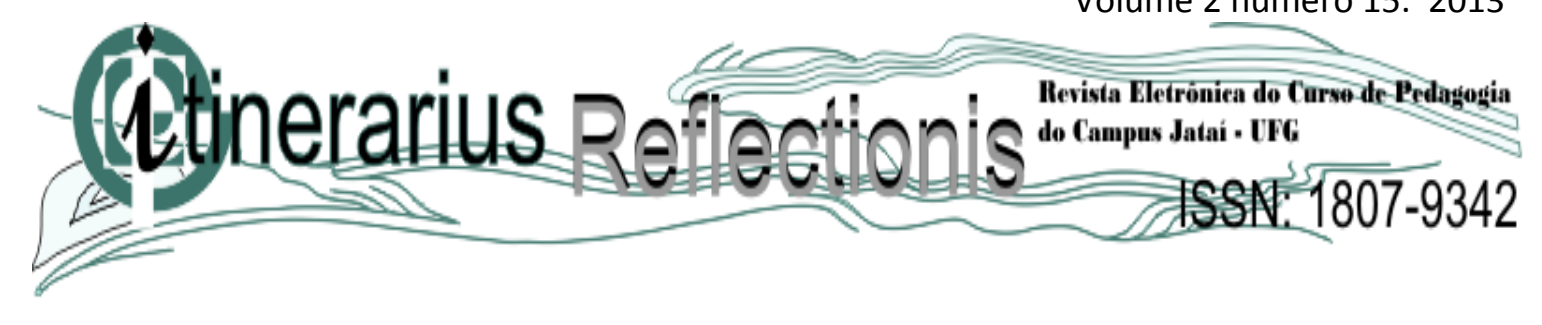

integrações conceituais e devem ser enfatizadas e dialogadas em sala de aula, reconhecidas pelo professor de forma positiva, pois a aprendizagem significativa ganha em qualidade à medida que o estudante reconhece novas relações conceituais.

As relações entre conceitos de maneira transversal também podem ser compreendidas como ligações cruzadas. Essas relações entre conceitos permite visualizar como um conceito em um domínio do conhecimento está relacionado a um conceito em outro domínio identificado no mapa. As ligações cruzadas usadas na criação de novos conhecimentos, para Moreira (2010), representam saltos criativos por parte do estudante. Existem duas características que são importantes na facilitação do pensamento criativo, segundo Novak e Cañas (2012), que são: a estrutura hierárquica que está representada em um mapa conceitual e a capacidade do estudante em pesquisar e caracterizar novas ligações cruzadas.

Novak e Gowin (1996) citam que a exposição de hierarquias no mapa indicia diferenciação progressiva e reconciliação integrativa. A ligação de conceitos, que de outro modo seriam considerados como independentes, podem sinalizar a ocorrência da reconciliação integrativa. Moreira (2010) afirma que na explicação do mapa, quando o estudante realizar movimento de sobe e desce nas hierarquias conceituais também indica reconciliação integrativa. Os mapas conceituais se apresentam como um instrumento, porém, não único para observar indícios da ocorrência de aprendizagem significativa. Sua utilização pode levar a pensar que se trata de uma fórmula de aplicação, contudo, segundo Novak e Gowin (1996) é preciso ser enquadrado como um modelo.

\subsection{Como pode ser usado o mapa conceitual}

O mapeamento conceitual é uma técnica muito flexível e em razão disso pode ser usado em diversas situações, para diferentes finalidades: instrumento de análise do currículo, técnica didática, recurso de aprendizagem, meio de avaliação (MOREIRA; BUCHWEITZ, 1993). Os mapas conceituais podem ser utilizados para diversos fins, como por exemplo: 


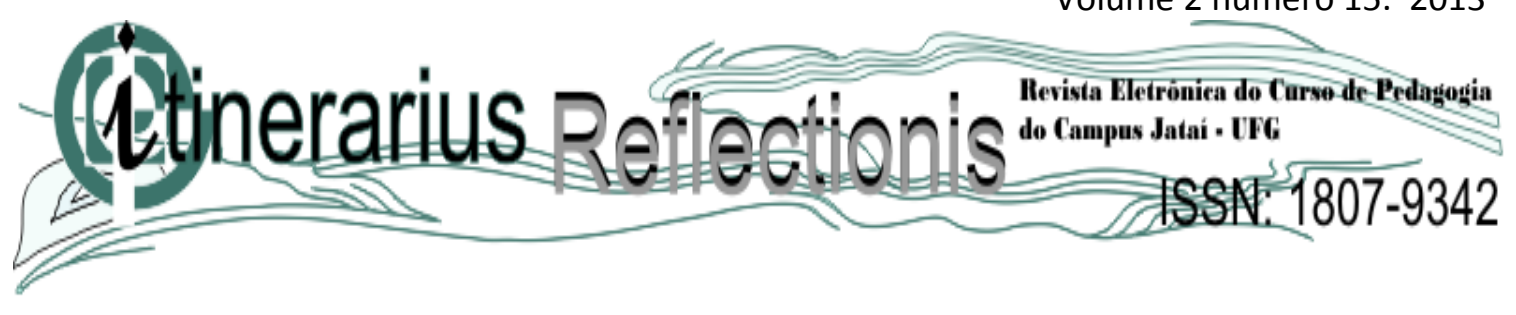

a) Para apresentação de um curso, conforme a figura 3 .

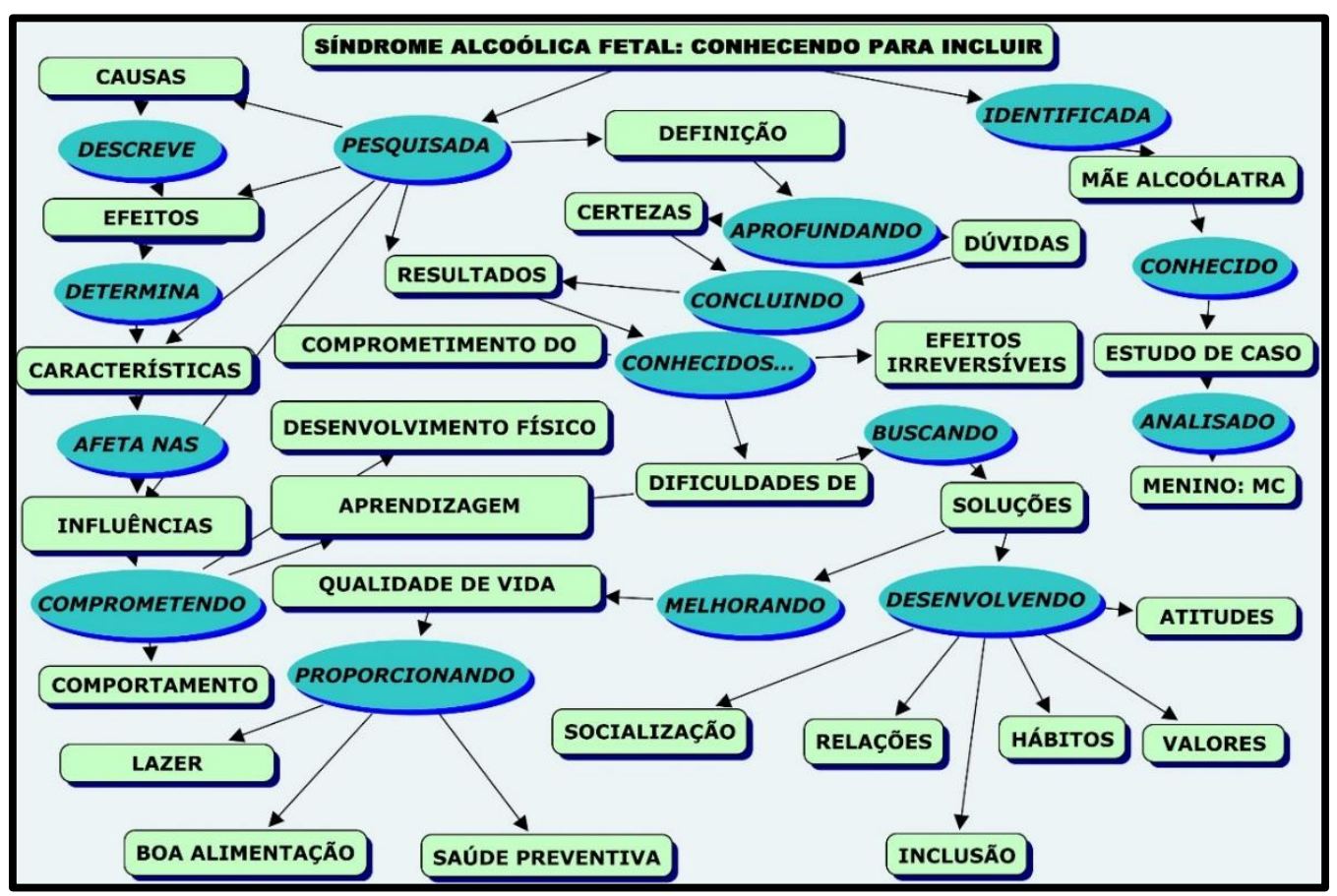

Figura 3: Curso de aperfeiçoamento, cujo tema abordado é Síndrome alcóolica.

Fonte: http://proavirtualg30.pbworks.com

O mapa conceitual acima é uma representação concisa da estrutura conceitual que está sendo ensinadas e, como tal, provavelmente facilitam a aprendizagem dessas estruturas. Entretanto, diferentemente de outros materiais didáticos, mapas conceituais não são auto-instrutivos: devem ser explicados pelo professor. Além disso, embora possam ser usados para dar uma visão geral do tema em estudo, é preferível usá-los quando os alunos já têm uma certa familiaridade com o assunto, de modo que sejam potencialmente significativos e permitam a integração, reconciliação e diferenciação de significados de conceitos (MOREIRA, 2010)

b) Para uma única aula, conforme figura 4, que apresenta o tema transgênico. 

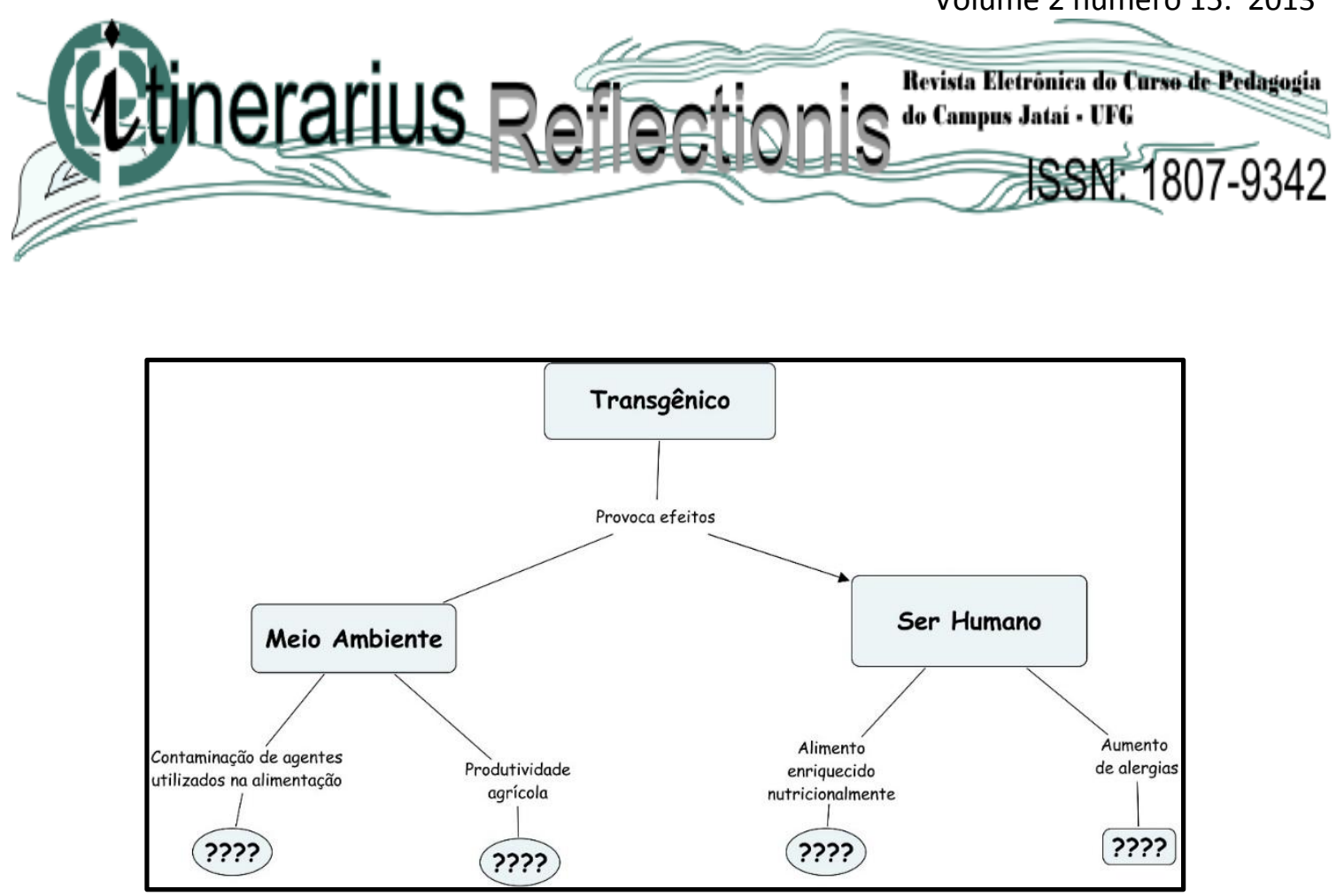

Figura 4: Mapa conceitual para apresentação em aula de Ciências, cujo tema é transgênico. Fonte: transgenicostrescachoeiras.pbworks.com

Um mapa envolvendo apenas conceitos gerais, inclusivos e organizacionais pode ser usado como referencial para o planejamento de um curso inteiro, enquanto que um mapa incluindo somente conceitos específicos, pouco inclusivos, pode auxiliar na seleção de determinados materiais instrucionais. Isso quer dizer que mapas conceituais podem ser importantes mecanismos para focalizar a atenção do planejador de currículo na distinção entre o conteúdo curricular e conteúdo instrumental, ou seja, entre o conteúdo que se espera que seja aprendido (MOREIRA, 2010).

$\mathrm{Na}$ medida em que os estudantes utilizarem mapas conceituais para integrar, reconciliar e diferenciar conceitos, na medida em que usarem essa técnica para analisar artigos, textos capítulos de livros, romances, experimentos de laboratório, e outros materiais educativos do currículo, eles estarão usando o mapeamento conceitual como um recurso de aprendizagem.

c) Para uma revisão bibliográfica, conforme figura 5. 

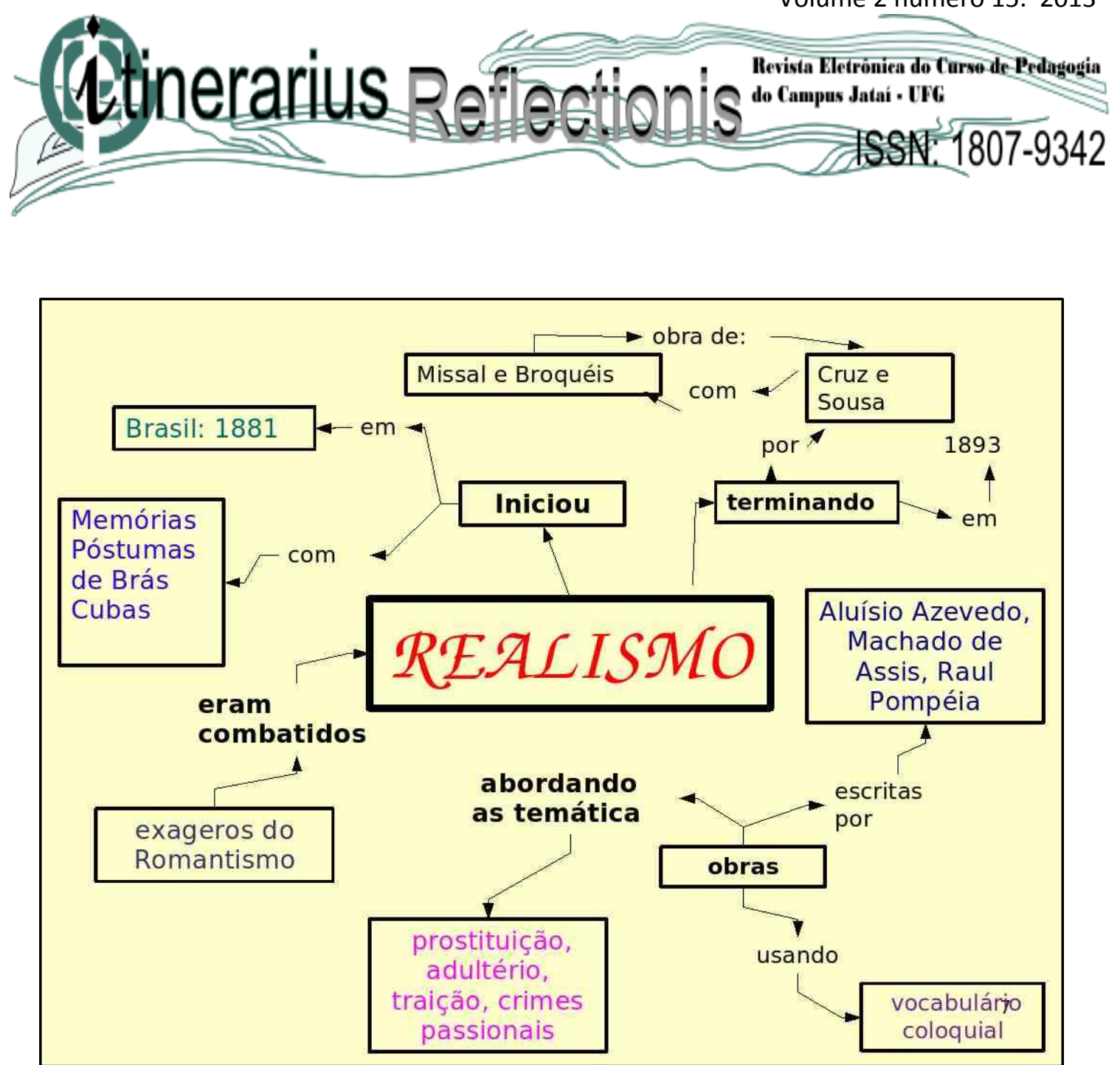

Figura 5: Mapa conceitual para apresentação a respeito do tema Realismo.

Fonte: dotti2008.pbworks.com

A revisão bibliográfica supõe a leitura, a análise e o devido registro das anotações mais importantes relacionadas aos documentos revisados. Os mapas conceituais, como organizadores de conhecimento, podem ser usados para representar o conhecimento de uma pessoa sobre um determinado assunto. Com base nessa possibilidade e na existência de ferramentas para a construção de mapas, pode-se usar os mapas como uma ferramenta de apoio ao professor e aos estudantes, para representar os conceitos importantes sobre um determinado artigo ou texto.

Dessa forma, os estudantes poderão fichar seus artigos na forma de mapas. Por outro lado, os professores terão em mãos mais um recurso para verificar a aprendizagem dos estudantes sobre os assuntos abordados, além de poderem comparar os vários mapas construídos pelos estudantes, a fim de identificarem a formação dos conceitos, conceitos mal formados, suas ideias e relações identificadas entre os conceitos, acompanhando assim a evolução do conhecimento do estudante. Essa forma de utilização de mapas é 


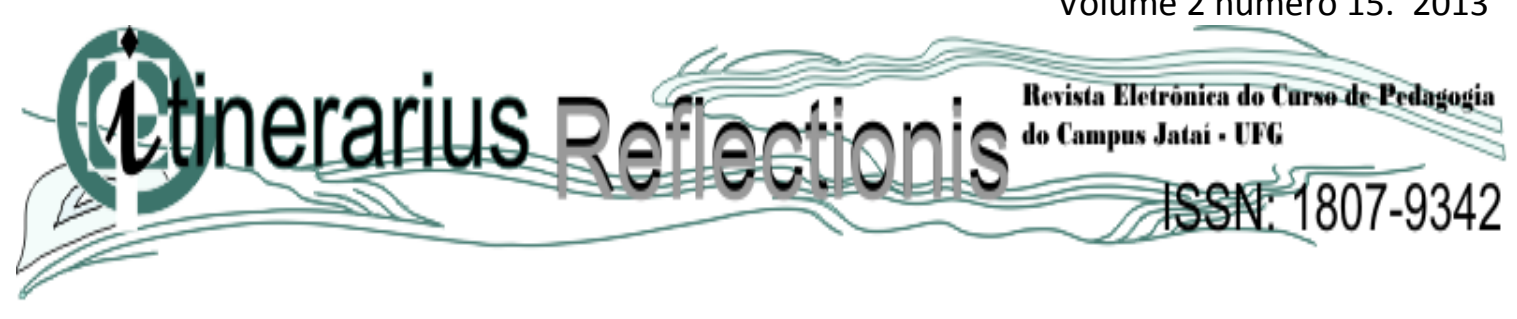

ainda um bom instrumento para facilitar o debate centrado na leitura de textos. Após a leitura de um texto, onde o estudante constrói progressivamente um mapa do conhecimento (re)construído por ele, os estudantes podem se reunir para debater o assunto, a partir da comparação dos mapas, identificando conceitos e ligações que um ou outro percebeu ou não. Eles podem ainda discutir sobre as ligações percebidas de forma diferente e, até mesmo, em situações conflitantes. Uma breve reflexão nos permite perceber as vantagens desta proposta sobre os debates apoiados em anotações isoladas.

d) Como indexadores de conteúdo, conforme figura 6 .

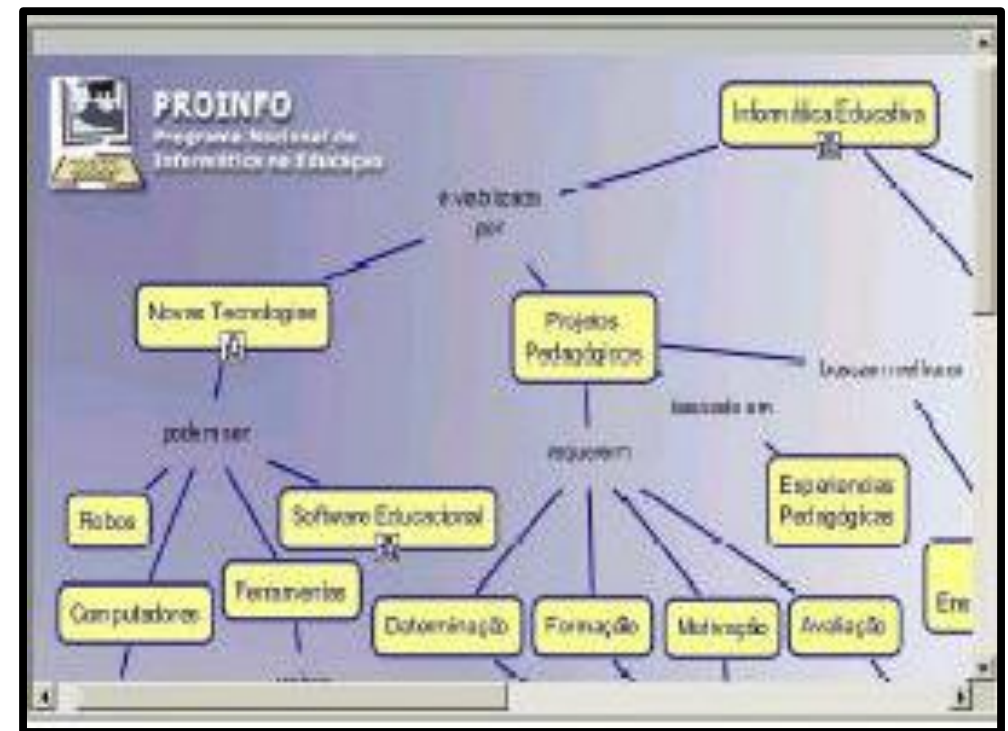

Figura 6: Página inicial do site para indexação de conteúdo sobre Informática educativa. Fonte: http://www.nte-jgs.rct-sc.br/mapas.htm

Os mapas conceituais apresentam-se sob a forma de conceitos interligados por seus relacionamentos. Com o uso de ferramentas adequadas para a construção de mapas, tal como o CMapTool, pode-se associar vários recursos aos nós de um mapa. Um destes recursos é associar uma coleção de documentos (texto, páginas web etc.) aos mapas, onde cada nó, que representa um conceito, pode ser associado a um ou mais documentos dessa coleção. Entretanto, essa associação é livre e fica a cargo do usuário dessas ferramentas. Desta forma, o mapa conceitual pode servir como um grande indexador de conteúdo. Essa é uma ferramenta cujo uso traz significativas contribuições no contexto 


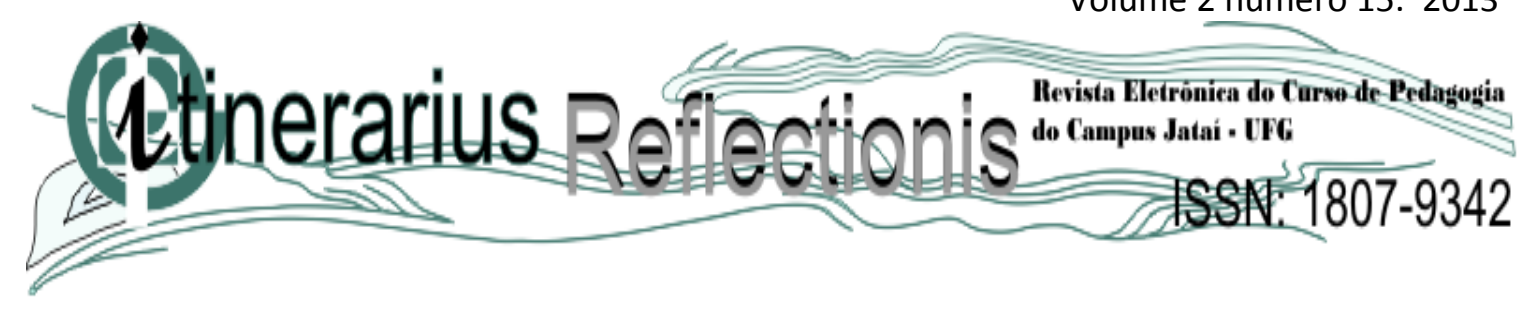

de ambientes virtuais de aprendizagem (AVA). Isso se dá pelo fato de que, em uma comunidade virtual suportada por estes ambientes, formam-se grupos que possuem sua própria coleção de documentos.

\section{Considerações finais}

Este artigo apresentou os mapas conceituais como um instrumento didático que pode ser muito útil na educação, em especial para a indexação de conteúdo, como apoio à revisão bibliográfica e como apoio ao desenvolvimento de projetos de aprendizagem.

Segundo Moreira (2010), apoiado em Ausubel, Novak e Hanesian (1980) quando se estrutura um conteúdo para ser apresentado ao estudante, é preciso proporcionar uma diferenciação progressiva, princípio ausubeliano pelo qual o conteúdo deve ser programado de forma que as ideias mais específicas sejam apresentadas inicialmente e, progressivamente diferenciadas. Outra característica importante a ser observada no mapa conceitual construído pelos estudantes são as ligações cruzadas.

Para Moreira (2010), corroborado por Penã et al. (2005), na elaboração do novo conhecimento, as ligações cruzadas que representam ligações entre conceitos em diferentes segmentos ou domínios do conhecimento, muitas vezes, evidenciam saltos criativos por parte do estudante. A ausência de ligações cruzadas e a consequente aparência ramificada denotam uma estrutura cognitiva pobre e mapas repletos de ligações cruzadas indicam uma estrutura mais rica.

Nesse sentido, os mapas conceituais se constituem em uma visualização de conceitos e relações hierárquicas entre eles, que pode ser muito útil tanto para o professor quanto para o estudante enquanto instrumento para exteriorizar seus conhecimentos. Não se trata de uma representação precisa e completa do conhecimento do estudante, mas sim, uma boa aproximação em termos de expressão. Para Ausubel, Novak e Hanesian (1980), muitas vezes, a dificuldade maior não está na discriminalidade, mas sim, na aparente contradição entre os conceitos novos e ideias já estabelecidas na estrutura cognitiva do estudante. Uma possível consequência desta 


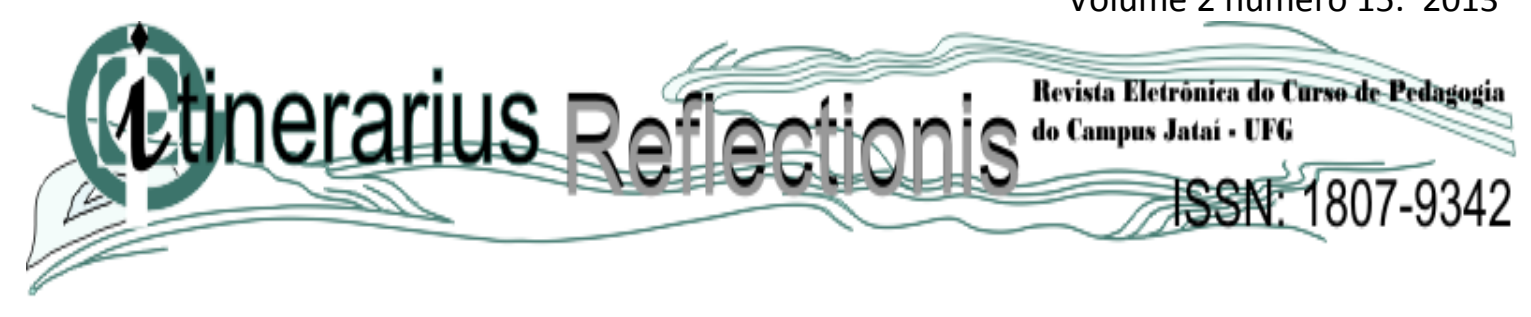

contradição é o descarte de uma nova proposição como válida, tentando colocá-la como aspecto isolado, sem conectar a conhecimentos anteriores.

Planejar uma disciplina ou um curso não é tarefa fácil, ainda mais para profissionais que não tiveram o devido preparo didático e pedagógico para utilizar esse tipo de instrumento, realidade que muitos docentes enfrentam com regularidade. Muito embora seja uma constatação, ainda é possível, por meio de formações continuadas, utilizar esse instrumento na sala de aula, a fim de apresentar determinado conteúdo.

\section{Referências}

AUSUBEL, D. P; NOVAK, J. D.; HANESIAN, H. Psicologia Educacional. Rio de Janeiro: Interamericana, 1980.

BEHRENS, M. A. O paradigma emergente e a prática pedagógica. Petrópolis, $6^{\mathrm{a}}$ ed. Vozes, 213.

COLL, C.; MARCHESI, A.; PALACIOS, J. Desenvolvimento psicológico e educação: psicologia da educação escolar. $2^{a}$. ed. Porto Alegre: Artmed, 2007.

DRYDEN, G.; VOS, J. Revolucionando o aprendizado. São Paulo: Makrom Books, 1996.

FERGUSON, M. Voar e ver: novos caminhos para o aprendizado. Rio de Janeiro, Record, 1992.

FERNANDES, J.V. Saberes, competências, valores e afectos necessários ao bom desempenho profissional do/a professoria. Lisboa: Plátano Edições Técnicas, 2001.

FREIRE, P. Pedagogia da autonomia. Saberes necessários à prática educativa. Rio de Janeiro: Paz e Terra, 1997.

LIBÂNEO, J.C. Adeus professor, adeus professora? Novas exigências educacionais e profissão docente. São Paulo: Cortez, 1998.

MOREIRA, M. A. Mapas conceituais e aprendizagem significativa. São Paulo: Centauro, 2010.

MOREIRA, M. A.; BUCHWEITZ, B. Novas estratégias de Ensino e Aprendizagem: mapas conceituais e o Vê epistemológico. Lisboa: Plátano, 1993.

MOREIRA, M. A.; MASINI, E. F. S. Aprendizagem significativa: A teoria de David Ausubel. São Paulo: Centauro, 2001. 


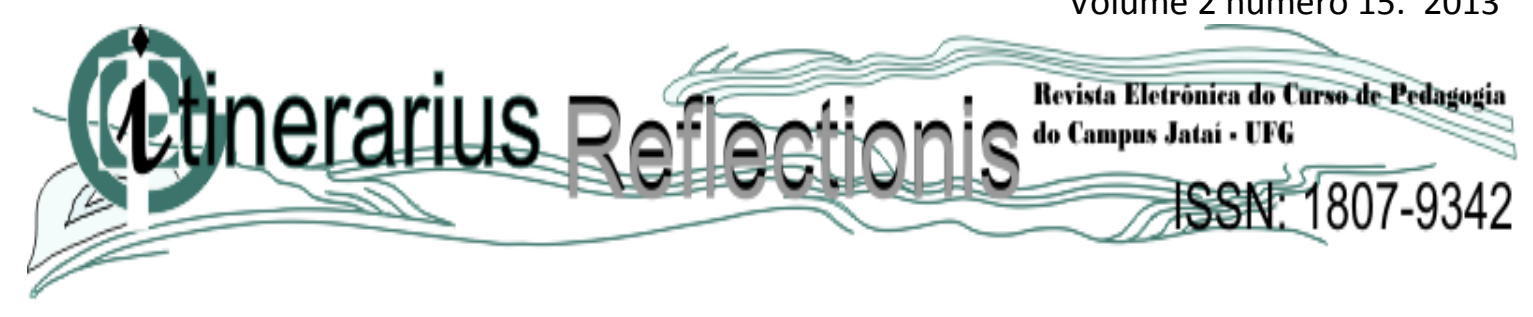

NOVAK, J. D.; CAÑAS, A. J. The Theory Underlying Concept Maps and How to Construct. Disponível em:< http://cmap.ihmc.us/TheoryConceptMaps.htm >. Acesso em: 11 set. 2013.

NOVAK, J. D.; GOWIN, B. D. Aprender a Aprender. Lisboa: Plátano Edições Técnicas, 1996.

PIMENTEL, M.G. O professor em construção. Brasília: Estudos e debates, 1993.

PENÃ, A. O., et al. Mapas conceituais: uma técnica para aprender. São Paulo: Loyola, 2005.

POZO, J. I. Teorias cognitivas da aprendizagem. $3^{\text {a }}$. ed. São Paulo: Artes Medicas, 1998.

VEIGA, I.A. Didática: o ensino e suas relações. Campinas: Papirus, 1996.

ZABALA, A. A prática educativa: como ensinar. Porto Alegre: Artmed, 2007. 